\section{BICUSPID AORTOPATHY OR BICUSPID AORTOPATHIES? THE RISK IN GENERALIZING To the Editor:}

We read with interest the article by Fazel and coworkers, ${ }^{1}$ which highlighted the previously underreported issue of transverse aortic arch involvement in aortopathy related to the bicuspid aortic valve (BAV). We totally agree with the authors' claim that the surgical approach to BAV aortopathy should be custom-tailored, inasmuch as different morphologic patterns can be encountered: this emerged also in our recent study on 280 BAV subjects. $^{2}$ However, their conclusion in favor of pre-emptive concomitant total arch replacement for the majority of BAV patients undergoing proximal aortic operations may raise concerns.

In a recent large series, ${ }^{3}$ the dilatation/aneurysm involved the arch in only $4.3 \%$ of BAV patients, versus $7.3 \%$ without BAV. The anticipation by Fazel's group ${ }^{1}$ that a proximal arch measuring $3.6 \mathrm{~cm}$ (as in "cluster IV, " including $45 \%$ of the study patients) will dilate to $5 \mathrm{~cm}$ within 15 years after ascending aortic replacement is not confirmed by clinical evidence. The $1.9 \mathrm{~mm} / \mathrm{y}$ growth rate that they mention actually refers to the mid-ascending tract, ${ }^{3}$ with the rate of arch size progression currently being unknown.

Unfortunately, this study lacks a comparison with matched subjects with a tricuspid aortic valve ${ }^{1}$ : thus

\footnotetext{
The Editor welcomes submissions for possible publication in the Letters to the Editor section that consist of commentary on an article published in the Journal or other relevant issues. Authors should: • Include no more than 500 words of text, three authors, and five references. - Type with double-spacing. - See http://jtcs.ctsnetjournals.org/misc/ifora.shtml for detailed submission instructions. - Submit the letter electronically via jtcvs.editorialmanager.com. Letters commenting on an article published in the JTCVS will be considered if they are received within 6 weeks of the time the article was published. Authors of the article being commented on will be given an opportunity of offer a timely response ( 2 weeks) to the letter. Authors of letters will be notified that the letter has been received. Unpublished letters cannot be returned.
}

the observed patterns may not be unique to the BAV setting, and the definition itself of arch dilatation was not done by comparison with normal values. Moreover, as evident from Figure $3,^{1}$ only cluster III (ascendingtarch pattern) was quite homogeneous in terms of transverse arch involvement, whereas many patients in cluster IV (root tascending \pm arch pattern) actually had small arch dimensions, in all comparable with those in cluster I (root pattern) or II (ascending pattern). However, the authors omitted a statistical comparison of aortic dimensions between clusters.

The BAV function and BAV morphology factors should be considered when trying to better discriminate subgroups of BAV aortopathy. In the Westhoff-Bleck magnetic resonance imaging study, ${ }^{4}$ only BAV patients with moderate-severe aortic regurgitation had significantly greater transverse arch size compared with matched controls, whereas in normally functioning BAV patients only root and ascending diameters were larger than in controls. Schaefer and colleagues $^{5}$ recently found right-left orientation of the BAV cusps (rightnoncoronary fusion) to be associated with a significantly larger proximal arch compared with anteroposterior orientation (right-left coronary fusion). Interestingly, in Fazel's report, the highest prevalence of the rightnoncoronary pattern and the highest mean grade of aortic insufficiency were observed in cluster III. In our ongoing magnetic resonance imaging study, 8 nonstenotic/nonregurgitant BAV subjects with right-left coronary fusion have been compared so far with matched controls, showing no significant difference in proximal $(24.3 \pm$ $2.8 \mathrm{~cm}$ vs $25.9 \pm 4.1 ; P=.36)$ and transverse arch size $(20.5 \pm 2.3 \mathrm{~cm}$ vs $22 \pm 3.1 ; P=.29$ ).

Different aortopathies may subtend the various possible patterns of BAVrelated aortic dilatation: probably it is not possible to issue general principles and recommendations on such a com- plex and multifaceted matter. The identification of a definite BAV phenotype representing a more "malignant" form of disease, amenable to more extensive surgical resections, still requires special research efforts.

\section{Alessandro Della Corte, MD Maurizio Cotrufo, MD Department of Cardiothoracic Sciences Second University of Naples V. Monaldi Hospital Naples, Italy}

\section{References}

1. Fazel SS, Mallidi HR, Lee RS, Sheehan MP, Liang D, Fleischman D, et al. The aortopathy of bicuspid aortic valve disease has distinctive patterns and usually involves the transverse aortic arch. J Thorac Cardiovasc Surg. 2008;135:901-7.

2. Della Corte A, Bancone C, Quarto C, Dialetto G, Covino FE, Scardone M, et al. Predictors of ascending aortic dilatation with bicuspid aortic valve: a wide spectrum of disease expression. Eur J Cardiothorac Surg. 2008;31:397-405.

3. Davies RR, Kaple RK, Mandapati D, Gallo A, Botta DM, Elefteriades JA, et al. Natural history of ascending aortic aneurysms in the setting of an unreplaced bicuspid aortic valve. Ann Thorac Surg. 2007;83:1338-44.

4. Westhoff-Bleck M, Meyer GP, Lotz J, Tutarel O, Weiss T, Rafflenbeul W, et al. Dilatation of the entire thoracic aorta in patients with bicuspid aortic valve: a magnetic resonance angiography study. Vasa. 2005;34:181-5.

5. Schaefer BM, Lewin MB, Stout KK, Byers PH, Otto CM. Usefulness of bicuspid aortic valve phenotype to predict elastic properties of the ascending aorta. Am J Cardiol. 2007;99:686-90.

doi:10.1016/j.jtcvs.2008.07.052

\section{Reply to the Editor}

We thank Della Corte and Cotrufo from Naples for their interest in our observations and for raising several critical points concerning the "aortopathy" associated with bicuspid aortic valve (BAV) disease. Owing to space limitations, we can only discuss the important question of extent of aortic resection at the time of operation, particularly in light of the recent condemnation of the more aggressive American College of Cardiology/ American Heart Association guidelines by Guntheroth. ${ }^{1}$ 
Primum non nocere. We agree with this principle and uphold it in our clinical practice. On all too numerous occasions we have surgically treated BAV patients who have undergone previous aortic valve replacement (AVR) with or without ascending aortic replacement who present with a large aortic arch aneurysm, pseudoaneurysm, or dissection, sometimes annealed to the posterior table of the sternum, which can mandate cooling and circulatory arrest before completing the redo sternotomy. These are challenging redo cases in the best of hands. The situation might possibly have been avoided if more complete resection of the dilated aorta at the time of initial procedure had been carried out. Della Corte and Cotrufo over the years have done a superb job describing the various histologic and pathologic characterizations of the aorta of patients with a BAV and have highlighted that a diseased aorta does not suddenly happen at the magical $5.0-\mathrm{cm}$ mark. The $5.0-\mathrm{cm}$ threshold is just an arbitrary diameter at which surgical results in average medical centers are projected to be superior to the natural history of the disease. But here, as always, is the rub: Guidelines are easy to apply to medical therapy, but application of guidelines to different surgeons who have variable degrees of experience with a given procedure and substantially different operative results may yield suboptimal patient management.

It is difficult to know whether harm has been done to a patient with BAV disease with marked dilatation of the ascending aorta and mild-moderate involvement of the arch who only underwent replacement of the ascending aorta and AVR electively. Conversely, harm will be done if the transverse arch is replaced in inexperienced centers when the arch dilatation is only modest. However, this raises the issue of who should do these procedures in the first place. It is clear from our and Westhoff-Bleck and coworkers' data ${ }^{2}$ that the aortop- athy of BAV disease extends into the aortic arch in a large fraction of patients with a BAV. We aim to provide a definitive surgical procedure at the time of the initial operation, which means complete resection of all weak and dilated thoracic aortas. This is justified by the facts outlined in our report that the incremental surgical risk to the patient is minimal or absent in our hands.

Let us consider the following numbers published by Januzzi and coworkers $^{3}$ from the International Registry of Aortic Dissection registry. In their database, 68 patients were younger than 40 years of age at the time of aortic dissection; of these 68 patients, $9 \%$ had a BAV. Importantly, $12 \%$ of patients had had a previous AVR at this young age. The aortic disease of those having undergone AVR is not described. It is likely that the majority of these patients had BAV disease given that degenerative aortic diseases are unlikely to present so early and that patients with the Marfan syndrome and severe aortic regurgitation owing to annuloaortic ectasia probably would have received full aortic root replacement earlier. If indeed this is the case, the majority of these patients were harmed by not having a complete resection of their diseased aortas at the time of AVR. This notion is supported by Borger and colleagues' conclusion $^{4}$ that leaving ascending aortas of 4.5 to $5.0 \mathrm{~cm}$ in diameter at the time of AVR for a BAV is dangerous and results in patient harm. More telling are the data reported by Russo and colleagues, ${ }^{5}$ who compared 50 patients with BAV to 50 similar patients with a tricuspid valve (TAV) after AVR. These patients were followed up for a maximum of 27 years. Of the 50 BAV patients, 7 suffered sudden death and 5 presented later with acute aortic dissection. At the time of presentation or follow-up, the mean aortic diameter in the BAV group was $4.6 \mathrm{~cm}$. None of the TAV patients sustained either complication. Although the natural history of asymp- tomatic BAV patients treated medically is relatively benign, as recently reported by Michelena and coworkers, ${ }^{6}$ it appears that surgically referred patients, as might be anticipated, may have a more malignant natural history.

In our patients with cluster IV aortic dilatation, the average aortic diameter was $3.6 \mathrm{~cm}$ at the takeoff of the innominate artery; traditional clamping of the aorta and replacement of the ascending aorta in such circumstances would leave behind at least a $4.0-\mathrm{cm}$ diameter aorta extending into the arch. In our minds, this is inadvisable and may cause harm over the long term. We believe that at a minimum the surgeon should perform an open distal anastomosis and resect some of the dilated, soft aortic arch. Our preference includes a sigmoid-shaped tailoring of the graft leaving only a narrow tongue of arch along the greater curve and arch branches; this "peninsula style" arch replacement removes almost the entire pathologic transverse arch without resorting to an endto-end distal aortic anastomosis and separate arch branch anastomoses. With adequate preparation, moderate hypothermia, and antegrade selective cerebral perfusion, this has been a safe and reproducible procedure in our hands for nearly 10 years and has been associated with very low morbidity and mortality rates, including stroke. It is unclear to us why this approach is avoided by many surgeons.

Given our experience, we continue to argue for a more aggressive stance regarding the aortopathy of BAV at the initial operation. We also recognize that simpler approaches might be safer at other centers where many dozens of arch replacements are not done each year, and we would hope that insightful surgeons would be honest in discussing with their patients individual risk versus benefit in treating this disease in his/her hands at his/her institution. However, the surgeon who leaves behind a substantial 
segment of dilated, abnormal aorta at the time of the first operation in a patient with BAV disease should recognize that he or she has most likely performed-for whatever reason-an incomplete procedure, something E. Stanley Crawford, MD, told us over 20 years ago was the "great surgical sin of omission."

\section{Shafie S. Fazel, MD, PhD \\ D. Craig Miller, $M D$ \\ Department of Cardiothoracic \\ Surgery \\ Stanford University Medical School Stanford, Calif}

\section{References}

1. Guntheroth WG. A critical review of the American College of Cardiology/American Heart Association practice guidelines on bicuspid aortic valve with dilated ascending aorta. Am J Cardiol. 2008;102 107-10.

2. Westhoff-Bleck M, Meyer GP, Lotz J, Tutarel O, Weiss T, Rafflenbeul W, et al. Dilatation of the entire thoracic aorta in patients with bicuspid aortic valve: a magnetic resonance angiography study. Vasa. 2005;34:181-5.

3. Januzzi JL, Isselbacher EM, Fattori R Cooper JV, Smith DE, Fang J, et al. Characterizing the young patient with aortic dissection: results from the International Registry of Aortic Dissection (IRAD). J Am Coll Cardiol. 2004;43: 665-9.

4. Borger MA, Preston M, Ivanov J, Fedak PW, Davierwala P, Armstrong S, et al. Should the ascending aorta be replaced more frequently in patients with bicuspid aortic valve disease? J Thorac Cardiovasc Surg. 2004;128:677-83

5. Russo CF, Mazzetti S, Garatti A, Ribera E, Milazzo A, Bruschi G, et al. Aortic complications after bicuspid aortic valve replacement: long-term results. Ann Thorac Surg. 2002;74:S1773-6.

6. Michelena HI, Desjardins VA, Avierinos JF, Russo A, Nkomo VT, Sundt TM, et al. Natural history of asymptomatic patients with normally functioning or minimally dysfunctional bicuspid aortic valve in the community. Circulation. 2008;117: 2776-84.

doi:10.1016/j.jtcvs.2008.08.027

\section{COMPUTED TOMOGRAPHY} AND ENDOSCOPIC ULTRASOUND IN DETECTION AND CHARACTERIZATION OF MEDIASTINAL MASSES

\section{To the Editor:}

We read with great interest the recent paper on bronchogenic cyst by Azeem, Rathwell, and Awad. ${ }^{1}$ They reported the case of a female patient with an intrapericardial bronchogenic cyst compressing the left main coronary artery who had acute severe coronary ischemia. Two weeks postoperatively a magnetic resonance imaging (MRI) study showed another cyst in the subcarinal position not compressing the nearby structures but requiring a second operation.

Bronchogenic cysts account for $6 \%$ to $15 \%$ of primary mediastinal masses. ${ }^{2}$ These lesions are usually detected incidentally by chest radiography or computed tomograpphy (CT), but in some cases they could present as an emergency, life-threatening situation. ${ }^{3}$ Symptoms of intrapericardial bronchogenic cysts can vary with the location and size of the mass and with the compression on the heart and vessels. If symptoms such as chest pain, shortness of breath, and arrhythmias are present, it is important to consider this rare entity in the differential diagnosis with coronary ischemia. ${ }^{2}$ Echocardiography and transesophageal echocardiography (TEE) are usually used to assess cardiac and paracardiac lesions. ${ }^{2,3}$ However, CT allows an accurate study of these lesions and above all their topographic relationship in order to plan the most appropriate surgical approach. ${ }^{4,5}$ MRI may also play a role when differential diagnosis from other mediastinal masses is difficult. ${ }^{3,5}$

For an accurate interpretation of this case study, it would be important to examine the following three questions:

1. In Figure 1 the authors affirm that the coronary angiogram showed severe compression of the ostium of the left main coronary artery. With the suspicion of external compression, a CT or TEE performed before the operation might have clarified the nature of the compression.

2. In the hypothesis that the coronary stenosis was caused by an extrinsic compression from a mass revealed by a perioperative TEE, were the bypass grafts necessary or could it have been better to check the patency of the left coronary artery after cyst removal?

In the discussion section the authors assert that the etiology of the mass was uncertain, but in our opinion this does not justify the bypass, especially because the coronary anatomy was normal.

3. Finally, we believe that the second cyst (sized $5 \times 3 \mathrm{~cm}$ ) was large enough to have been detected by the perioperative TEE, avoiding the second operation.

Actually, the thoracic CT and the endoscopic ultrasound allow the surgeon to have a correct preoperative diagnosis in the mediastinal lesions to use the most appropriate surgical approach. ${ }^{5}$

Ugo Cioffi, $M D, P h D^{a}$

Matilde De Simone, $M D, P h D^{a}$

Michele M. Ciulla, $M D, P h D^{b}$

Department of Surgery ${ }^{a}$

Istituto di Medicina Cardiovascolare

Centro di Fisiologia Clinica e Ipertensione $^{b}$

Fondazione IRCCS Ospedale Maggiore Policlinico Mangiagalli e Regina Elena University of Milan Milan, Italy

\section{References}

1. Azeem F, Rathwell C, Awad WI. A near fatal presentation of a bronchogenic cyst compressing the left main coronary artery. $J$ Thorac Cardiovasc Surg. 2008;135:1395-6.

2. Kobza R, Oechslin E, Jenni R. An intrapericardial bronchogenic cyst. Interact Cardiovasc Thorac Surg. 2003;2:279-80.

3. Lugo-Olivieri CH, Schwartzman GJ, Beall DP, Lima JAC, Fishman EK. Intrapericardial bronchogenic cyst: assessment with magnetic resonance imaging and transesophageal echocardiography. Clin Imaging. 1999;23:81-4.

4. Cardinale M, Ardissone F, Cataldi A, Gned D, Prato A, Solitro F, et al. Bronchogenic cysts in the adult: diagnostic criteria derived from the correct use of standard radiography and computed tomography. Radiol Med. 2008;113:385-94.

5. Cioffi U, Bonavina L, De Simone M, Santambrogio L, Pavoni G, Testori A, et al. Presentation and surgical management of bronchogenic and esophageal duplication cysts in adults. Chest. 1998;113:1492-6

doi:10.1016/j.jtcvs.2008.07.051 